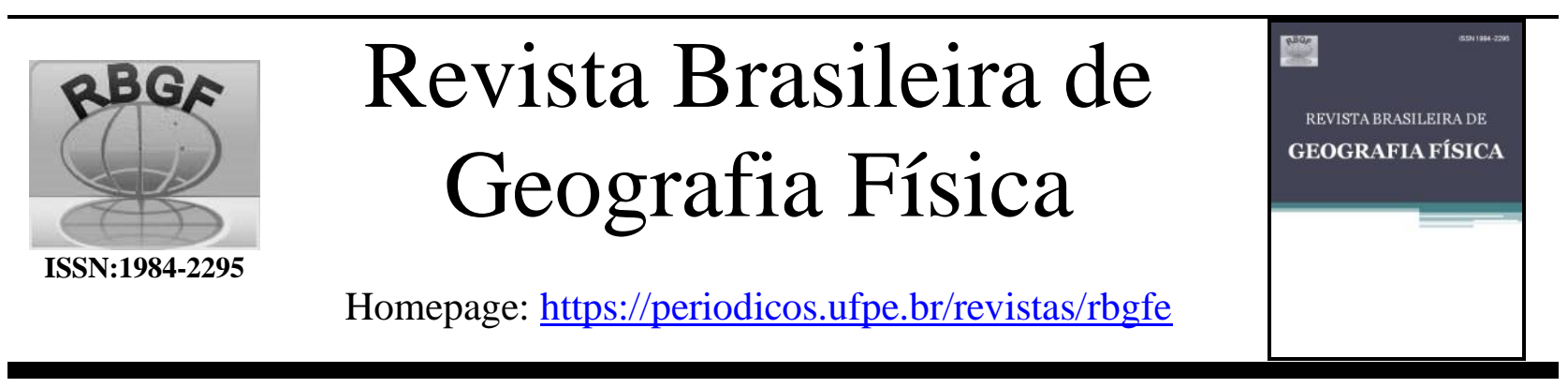

\title{
Índices de (des)conforto humano em um município de clima semiárido
}

\author{
Rebecca Luna Lucenaํㅜ Jório Bezerra Cabral Júnior² e Ercília Torres Steinke ${ }^{3}$
}

${ }^{1}$ Profa. Dra. do Programa de Pós-Graduação em Geografia (GEOCERES) e do Departamento de Geografia do Centro de Ensino Superior do Seridó (DGC/CERES/ Campus Caicó), ambos da Universidade Federal do Rio Grande do Norte (UFRN). Rua José Evaristo, Penedo, Caicó/RN - Brasil, CEP: 59300-000, e-mail: rebeccaosvaldo@yahoo.com.br; 2Prof. Dr. do Instituto de Geografia, Desenvolvimento e Meio Ambiente (IGDEMA), Universidade Federal de Alagoas (UFAL), Campus A.C. Simões (Maceió/Sede). Av. Lourival de Melo Mota, Bairro Cidade Universitária, Maceió/AL Brasil, CEP 57072-970, e-mail: jorio.cabral@gmail.com;

3Profa. Dra. Programa de Pós-Graduação em Geografia, Universidade de Brasília (UnB), Brasília, DF, Brasil. ICC Ala Norte - módulo 23 - campus universitário Darcy Ribeiro, CEP: 70910-900 - Brasilia, DF - Brasil, e-mail: ercilia@unb.br;

Artigo recebido em 07/04/2020 e aceito em 15/12/2020

R E S U M O

O objetivo principal neste trabalho consistiu em analisar e comparar índices de (des) conforto térmico humano em um município de clima semiárido. Para isso foram adquiridos e utilizados equipamentos termo-higrômetros automáticos datalogger Akso AK170, sendo esses distribuídos espacialmente em onze pontos (dez em áreas urbanizadas e um em área rural), durante um período de 32 dias, em Caicó-RN. De posse dos dados horários de temperatura e umidade relativa do ar (maio/junho), realizaram-se análises estatísticas descritivas e aplicaram-se três índices de conforto humano, a saber: Índice de Desconforto (ID), índice de Temperatura Efetiva (TE), e o Índice de Temperatura e Umidade (ITU). Os resultados indicaram que o município de Caicó está propenso aos efeitos do processo de urbanização, registrando-se frequências de temperaturas mais elevadas nas áreas urbanizadas, especialmente nas de menor arborização e maior concentração de pavimentos urbanos. Em termos médios a maior parte da população de Caicó sente desconforto devido ao calor (ID), as temperaturas ficaram sempre acima do considerado calor moderado (TE) e de acordo com o ITU a classificação foi de extremamente desconfortável. Portanto, é imprescindível minimizar o os efeitos da ilha de calor no município a fim de se obter melhores índices de conforto térmico humano.

Palavras-Chave: Clima urbano. Caicó-RN. Índices de conforto térmico humano.

\section{Human (dis) comfort indices in a semi-arid municipality in Brazil}

\begin{abstract}
A B S T R A C T
The main aim of this study was to analyse and compare the human thermal (dis)comfort indices in a Brazilian municipality with a semi-arid climate: Caicó, in the state of Rio Grande do Norte. Akso AK170 thermo-hygrometer data loggers were acquired for this purpose, which were distributed at eleven points in the study area - ten in built-up areas and one in a rural area - over a 32-day period covering the months of May to June. Having collected the time- and date-stamped temperature and relative humidity data, descriptive statistical analyses were conducted using three human comfort indices: discomfort index (DI), effective temperature index (ETI), and temperature-humidity index (THI). The results indicate that the municipality under study is affected by urbanization processes that propitiate higher temperatures in the built-up areas, especially where there are fewer trees and more of the roads are paved. On average, most of the population of Caicó feels discomfort because of the heat (ID), and the temperature always remains above the range rated as moderately hot (ETI). The municipal climate was classified as "extremely uncomfortable" by the THI. It is therefore of the utmost importance to minimize the effects of the heat island in the municipality to improve the human thermal comfort indices. Keywords: Urban climate. Caicó-RN. Human thermal comfort indices.
\end{abstract}




\section{Introdução}

Os estudos de clima urbano vêm sendo realizados por todo o mundo desde algumas dezenas de anos, tendo sido mais expressivos após a revolução industrial, com foco, entre outras abordagens, na análise térmica e na poluição atmosférica nas cidades industrializadas. Os estudos de Landsberg (1956), Monteiro, (1976), Lombardo, (1985), Taha (1997), Gartland (2010), são alguns exemplos de trabalhos nacional e internacionalmente reconhecidos, em que se apontava uma "atmosfera diferente" sobre e no ambiente urbanizado.

No Brasil, os estudos do clima urbano ganharam notoriedade através dos trabalhos de Carlos A. F. Monteiro e de Magda A. Lombardo quando da publicação dos seus trabalhos "Teoria e Clima Urbano" e "Ilhas de Calor das Metrópoles", respectivamente (Zavattini, 2004). A tese de Carlos A. F. Monteiro trouxe uma proposta de delimitação para os estudos do clima urbano focados em três distintos campos, conforme afirma Monteiro (1976; 2003): O campo hídrico-meteórico, abarcando os meteoros de impacto; o campo térmico-higrométrico, com abordagem nas condições térmicas e de conforto humano; e o campo físico-químico, trabalhando com aspectos relacionados a poluição do ar. Esses três campos, muito importantes do ponto de vista humano, são abordados sob uma mesma perspectiva: a de que na área urbanizada as condições atmosféricas divergem de seu entorno, ou seja, existe no ambiente urbano uma atmosfera diferente que mesmo vinculada aos sistemas sinóticos de grande e média escala, diverge desses sistemas maiores por apresentar peculiaridades oriundas das características do sítio urbano.

Nas grandes metrópoles, estudos comprovam que, de fato, as características atmosféricas se mostram distintas daquelas das áreas de entorno com aspectos rurais e florestais. $\mathrm{O}$ que, de modo geral, pode ser atribuído ao clima urbano são as seguintes características: uma área central mais aquecida que o entorno "ilha de calor"; uma atmosfera mais poluída que o entorno; impactos pluviométricos intensos mais catastróficos que o entorno (Taha, 1997; Monteiro, 2003; Gartland, 2010). Outros estudos ainda relatam a existência de mudanças no teor de umidade e na direção e velocidade dos ventos quando se compara o sitio urbano com áreas naturais ou rurais.

É conhecido que existe uma maior diferença entre o ambiente urbanizado e o seu entorno, quanto maior e mais modificada for a natureza do sitio urbano. Landsberg (1956) relatou que mesmo uma rua é capaz de produzir condições específicas de clima urbano. Essa característica é nitidamente observada à medida em que há áreas densamente construídas e pouco arborizadas (Shashua-Bar et al., 2010; Ting, 2012; Maskooni et al, 2020). A substituição gradual das áreas verdes por áreas residenciais e comerciais em diversas cidades do Brasil e do mundo vêm resultando num aumento significativo da temperatura do ar nas áreas urbanas (Correia et al 2019). Assim sendo, não apenas às metrópoles se torna importante estudos dessa natureza, mas também em cidades de médio e pequeno porte, uma vez que as principais repercussões desses efeitos são percebidas pela população com manifestações capazes de desorganizar a vida da cidade e deteriorar a qualidade de vida de seus habitantes (Monteiro, 1976).

Em se tratando do campo térmico nos estudos de clima urbano, para as cidades localizadas nas zonas intertropicais, tais estudos se tornam ainda mais relevantes, uma vez que essas áreas concentram a maior quantidade de energia comparada as regiões de latitudes médias e altas. Contudo, o processo de urbanização propicia o surgimento de ilhas de calor intensificando o desconforto térmico à população local, especialmente em municípios de clima semiárido, onde são observadas elevadas temperaturas do ar e ausência de chuvas na maior parte do ano (Cabral Júnior et al., 2013; Almeida e Cabral Júnior, 2014; Lucena et al., 2018; Cabral Júnior et al., 2019; Silva et al., 2020). Ressalta-se ainda que as condições de ambiente urbanizado, quando inadequadas, ocasionam condições climáticas próprias e perda da qualidade de vida para uma parcela da população (Lamberts et al., 1997; Andreasi et al., 2010). Essas situações associadas, urbanização e ambiente semiárido quente, podem estar promovendo intensificação no desconforto humano, principalmente em horários cujas temperaturas tendem a ser mais elevadas (entre 10 e $15 h)$.

Diante desse contexto, o objetivo principal neste trabalho foi o de analisar o comportamento higrotérmico de um município inserido no semiárido, Caicó, RN, comparando-se dados de temperatura e umidade relativa do ar e índices de (des) conforto térmico humano distribuídos em 11 pontos da cidade (zona urbana) e um ponto localizado em área periférica (zona rural). A escolha dos pontos foi feita a partir de estudos que tratam das características geográficas, topográficas, arquitetônicas da cidade, 
comparando-se em seguida, os diferentes pontos entre si.

\section{Material e métodos}

\section{Área de estudo}

$\mathrm{Na}$ Figura 1 verifica-se a localização geográfica com a caracterização climática (pluvial e térmica) da área de estudo, localizada no município de Caicó ( $6^{\circ} 27^{\prime} 35^{\prime \prime}$ Sul, $37^{\circ} 05^{\prime}$ 56" Oeste e $161 \mathrm{~m}$ de altitude), inserida na região Semiárida do Nordeste do Brasil e estado do Rio Grande do Norte (RN).
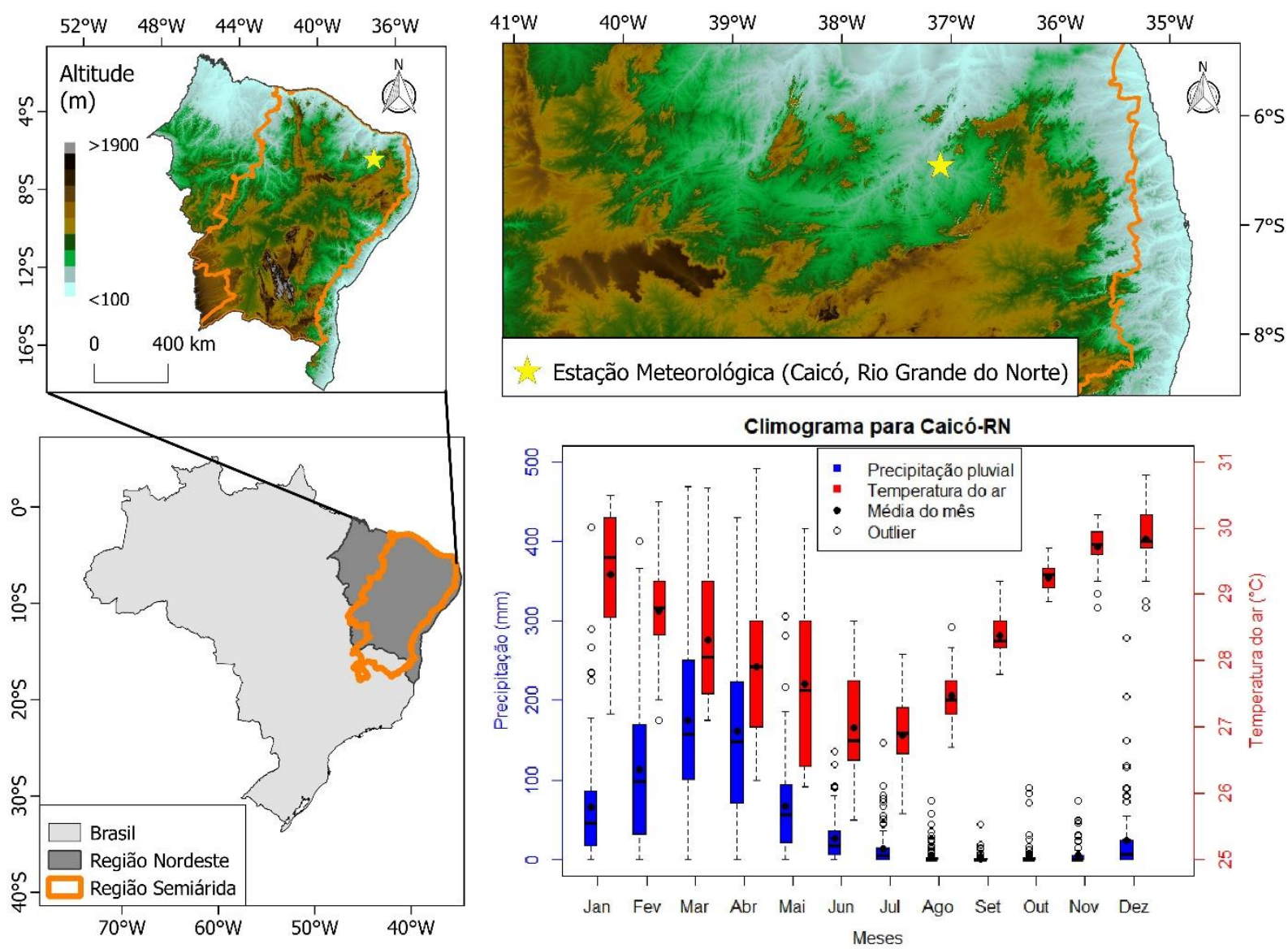

Figura 1. Localização da área de estudo, Caicó-Rio Grande do Norte, com as respectivas características hipsométricas e climáticas (referente a $3^{\circ}$ normal climatológica, 1981-2010). Fonte: Cabral Júnior e Lucena (2020).

A escolha da área de estudo se deve pela importância da cidade para a região e também por suas condições geográficas e climáticas. Caicó é um município de pequeno porte, com uma população estimada de 67.554 habitantes de acordo com o Instituto Brasileiro de Geografia e Estatística (IBGE, 2018), é o sétimo mais populoso do $\mathrm{RN}$ e obtém uma área de aproximadamente $1.228 \mathrm{Km}^{2}$. É o município mais importante da microrregião do Seridó tanto paraibano quanto o norte-rio-grandense, estando a $282 \mathrm{~km}$ de distância da capital Natal.

Está localizado na depressão sertaneja, área deprimida do Nordeste setentrional do Brasil, e conforme Ab'Saber (2003), representa o "verdadeiro semiárido", as depressões interplanálticas recobertas de vegetação Caatinga, rica em espécies xerófitas, com solos pedregosos e formações testemunhas de inselbergs. Por se situar em baixa latitude e altitude, aproximadamente 200km de distância do mar (ao norte) e devido aos padrões de circulação atmosférica atuantes, tais condições conferem a Caicó um tipo climático quente e semiárido (MOLION; BERNARDO, 2002; REBOITA et al., 2016).

A temperatura média anual do município é de $28,4^{\circ} \mathrm{C}$, com média da máxima de $35^{\circ} \mathrm{C}$ e média da mínima de $24,5^{\circ} \mathrm{C}$. A amplitude média diária é de $10^{\circ} \mathrm{C}$, sendo maior nos meses secos. A média pluviométrica anual é de $659 \mathrm{~mm}$ com forte 
variabilidade interanual no total de chuvas (Lucena et al., 2012; Lucena et al., 2013; 2016; Cabral Júnior e Lucena, 2020). O clima semiárido onde está inserido é produto das taxas de precipitação em combinação com a elevada insolação (média de 3.800 horas/ano) que de acordo com Lucena et al. (2018) gera alta evaporação das águas (média de $3000 \mathrm{~mm}$ anuais). Para Cabral Júnior e Bezerra (2018) isso culmina em um elevado déficit hídrico, sazonal e anualmente, destacando-se que Caicó encontra-se, de acordo com esses autores, na subregião do Nordeste brasileiro cujo potencial de perda de água por evapotranspiração de referência e o Índice de Aridez (IA) são os mais elevados.

Determinação dos pontos para instalação dos equipamentos e coleta dos dados

Sob condições de clima semiárido quente se desenvolveu o município de Caicó, que seguiu o mesmo ritmo da urbanização brasileira que teve grande impulso a partir da década de 1950 (FARIA, 2011). Logo, a expansão urbana foi ampliada: atualmente Caicó possui uma região central, com várias ruas asfaltadas e calçadas, forte densidade de construções que diminuem à medida que se afasta do seu centro.

Os 11 pontos analisados neste trabalho, destacados na Figura 2 (imagem capturada do Google Earth), do referido município, foram monitorados com intervalos de tempo de uma em uma hora, verificando-se a variação da temperatura e umidade relativa do ar, conforme critérios propostos por Romero (2013), considerando-se os "princípios bioclimáticos para o desenho urbano".

$\mathrm{Na}$ Tabela 1, verifica-se as características dos referidos pontos onde foram instalados os equipamentos.

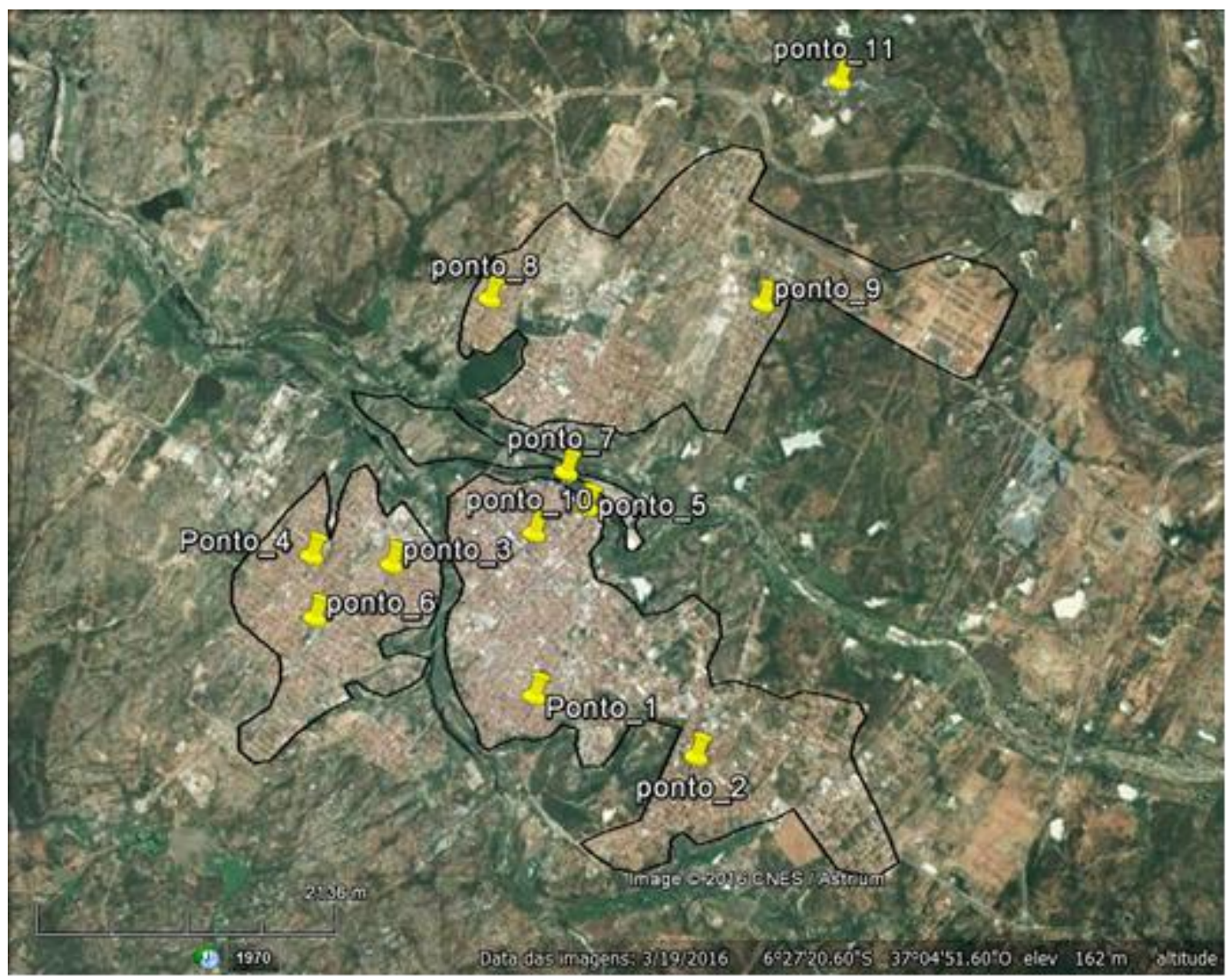

Figura 2. Imagem do Google Earth, adaptada pelos autores. 
Tabela 1. Distribuição e referência dos pontos com as respectivas coordenadas geográficas, altitude $(\mathrm{m})$ e características principais.

\begin{tabular}{|c|c|c|c|c|}
\hline Pontos & Nome/referência & Coordenadas & $\begin{array}{l}\text { Altitude } \\
\quad(\mathbf{m})\end{array}$ & Características principais \\
\hline $\mathrm{P} 1$ & $\begin{array}{l}\text { Nascente } \\
\text { (Paraíba) }\end{array}$ & $\begin{array}{l}06^{\circ} 28^{\prime} 17^{\prime}, \mathrm{S} \\
37^{\circ} 05^{\prime} 41^{\prime \prime} \mathrm{O}\end{array}$ & 185 & $\begin{array}{l}\text { Rua larga calçada, sem árvores, posição } \\
\text { nascente }\end{array}$ \\
\hline $\mathrm{P} 2$ & $\begin{array}{l}\text { Poente } \\
\text { (Coacal) }\end{array}$ & $\begin{array}{l}06^{\circ} 28^{\prime} 28^{\prime}, \mathrm{S} \\
37^{\circ} 05^{\prime} 01^{\prime}, \mathrm{O}\end{array}$ & 192 & $\begin{array}{l}\text { Rua larga calçada, sem árvores, posição } \\
\text { poente }\end{array}$ \\
\hline P3 & $\begin{array}{c}\text { Vale } \\
\text { (João XXIII) }\end{array}$ & $\begin{array}{l}06^{\circ} 27^{\prime} 49^{\prime \prime} \mathrm{S} \\
37^{\circ} 06^{\prime} 18^{\prime \prime} \mathrm{O}\end{array}$ & 164 & Rua calçada, fundo de vale, posição sul \\
\hline $\mathrm{P} 4$ & $\begin{array}{l}\text { Alto pedra } \\
\text { (Picanço) }\end{array}$ & $\begin{array}{l}06^{\circ} 27^{\prime} 48^{\prime}, \mathrm{S} \\
37^{\circ} 06^{\prime} 37^{\prime}, \mathrm{O}\end{array}$ & 192 & $\begin{array}{l}\text { Ponto elevado, topo de encosta sobre } \\
\text { granito, posição nascente }\end{array}$ \\
\hline P5 & $\begin{array}{l}\text { Rua estreita } \\
\text { (Centro) }\end{array}$ & $\begin{array}{l}06^{\circ} 27^{\prime} 32^{\prime \prime}, \mathrm{S} \\
37^{\circ} 05^{\prime} 33^{\prime \prime} \mathrm{O}\end{array}$ & 175 & $\begin{array}{l}\text { Rua muito estreita calçada, sem árvores, } \\
\text { densamente habitada, posição sudeste }\end{array}$ \\
\hline P6 & $\begin{array}{l}\text { Alto terra } \\
\text { (CAIC) }\end{array}$ & $\begin{array}{l}06^{\circ} 28^{\prime} 03^{\prime \prime} \mathrm{S} \\
37^{\circ} 06^{\prime} 34^{\prime \prime} \mathrm{O}\end{array}$ & 180 & $\begin{array}{l}\text { Ponto elevado, topo de encosta sobre solo } \\
\text { natural, posição norte }\end{array}$ \\
\hline $\mathrm{P} 7$ & Rua arborizada (Centro) & $\begin{array}{l}06^{\circ} 27^{\prime} 24^{\prime \prime}, \mathrm{S} \\
37^{\circ} 05^{\prime} 38^{\prime \prime} \mathrm{O}\end{array}$ & 160 & $\begin{array}{l}\text { Rua estreita calçada, completamente } \\
\text { arborizada, posição poente }\end{array}$ \\
\hline P8 & Rua de barro (Recreio) & $\begin{array}{l}06^{\circ} 26^{\prime} 43^{\prime \prime} \mathrm{S} \\
37^{\circ} 06^{\prime} 01^{\prime}, \mathrm{O}\end{array}$ & 160 & $\begin{array}{l}\text { Rua larga de barro, sem árvore, posição } \\
\text { nascente }\end{array}$ \\
\hline P9 & $\begin{array}{l}\text { Periferia } \\
\text { (Samanaú) }\end{array}$ & $\begin{array}{l}06^{\circ} 26^{\prime} 39^{\prime \prime} \mathrm{S} \\
37^{\circ} 04^{\prime} 54^{\prime \prime} \mathrm{O}\end{array}$ & 174 & $\begin{array}{l}\text { Periferia, rua levemente estreita e calçada, } \\
\text { sem árvore, posição nascente, próximo a } \\
\text { área verde }\end{array}$ \\
\hline P10 & $\begin{array}{l}\text { Avenida principal } \\
\text { (Coronel Martiniano) }\end{array}$ & $\begin{array}{l}06^{\circ} 27^{\prime} 39^{\prime \prime} \mathrm{S} \\
37^{\circ} 05^{\prime} 44^{\prime \prime} \mathrm{O}\end{array}$ & 161 & $\begin{array}{l}\text { Rua asfaltada, parcialmente sombreada, } \\
\text { posição norte }\end{array}$ \\
\hline P11 & $\begin{array}{c}\text { Área rural } \\
\text { (pousada Céu Azul) }\end{array}$ & $\begin{array}{l}06^{\circ} 25^{\prime} 43^{\prime \prime} \mathrm{S} \\
37^{\circ} 04^{\prime} 58^{\prime \prime} \mathrm{O}\end{array}$ & 178 & $\begin{array}{l}\text { Afastada da área urbana, aspecto rural, solo } \\
\text { natural, posição norte }\end{array}$ \\
\hline
\end{tabular}

\section{Parâmetros analisados e equipamentos utilizados}

Para analisar as características do clima urbano de Caicó neste trabalho, focou-se no campo higrotérmico (temperatura, em ${ }^{\circ} \mathrm{C}$, e a umidade relativa do ar, em \%). Foram utilizados onze termohigrômetros automáticos datalogger da marca Akso AK170 para registrar os dados horários de temperatura e umidade relativa do ar (24h/d-1), no período de trinta e dois dias (05/05/2016 a 05/06/2016).

Para instalação dos termo-higrômetros foram feitos abrigos meteorológicos que seguiram normas internacionais, que conforme Neves et al. (2015) são necessários abrigos de forma a minimizar as interferências externas como a incidência direta da chuva, radiação solar e aerossóis; ao mesmo tempo que devem permitir a ventilação e a dissipação rápida de calor. Os abrigos foram feitos com canos de Policloreto de Vinila (PVC) e com um ralo de PVC branco a uma altura média de 1.70 metros onde os termohigrometros foram colocados internamente. $\mathrm{Na}$ Figura 3 é identificado o aspecto dos abrigos construídos e o equipamento utilizado. 
Figura 3 - Termohigrômetros automáticos tipo Akso AK170, e os respectivos abrigos.
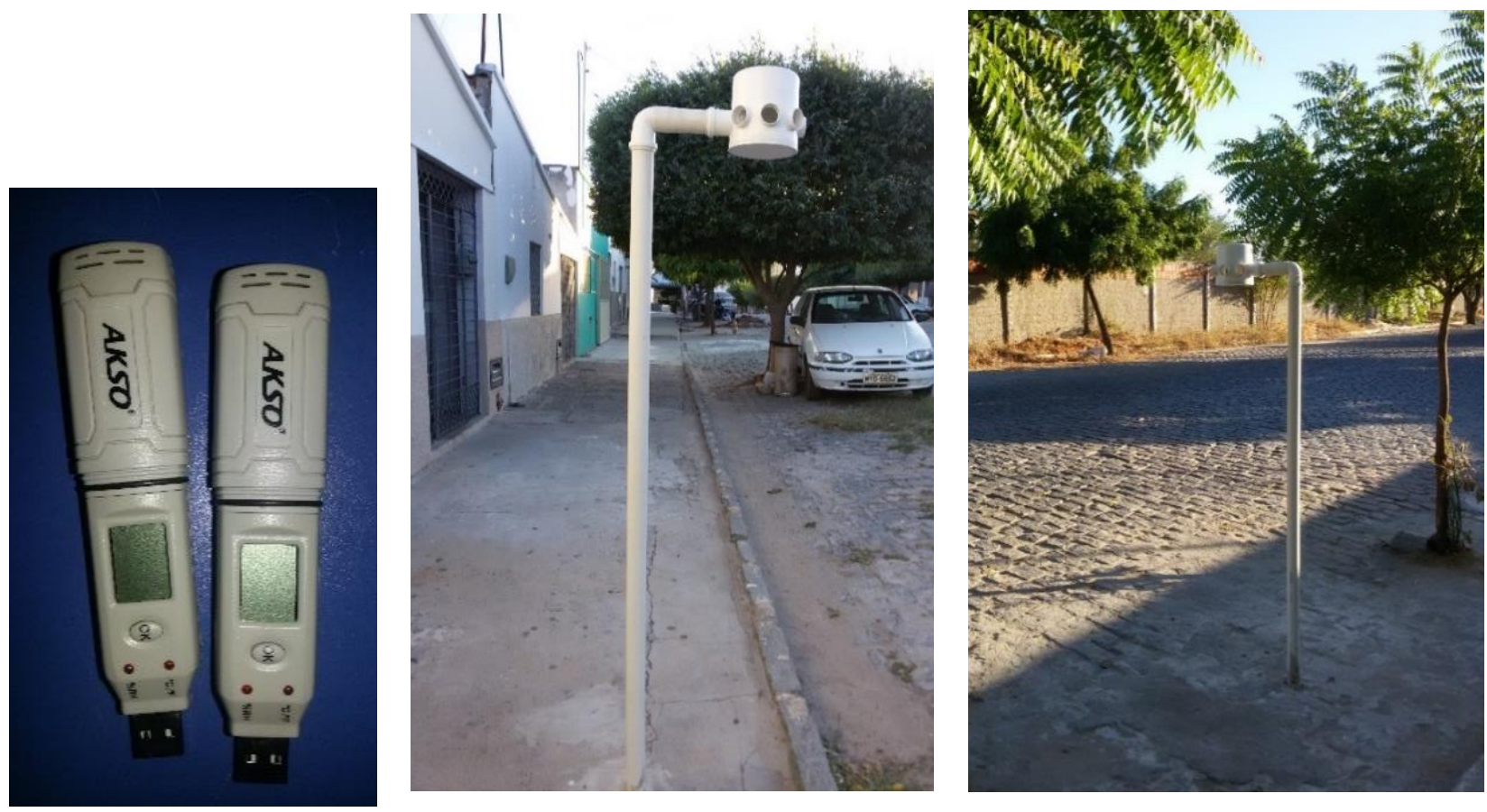

Análise estatística e aplicação de índices de conforto térmico humano

De posse dos dados higrotérmicos foram realizadas análises através da estatística descritiva: Valor Máximo, Valor Mínimo, Amplitude Total, Média Aritmética e Coeficiente de Variação.

Posteriormente foram aplicados três índices de conforto térmico humano: O Índice de Desconforto (ID), O Índice de Temperatura Efetiva (TE), o Índice de Temperatura e Umidade (ITU).

Segundo Silva (2007) o conforto térmico num determinado ambiente pode ser definido como a sensação de bem-estar experimentada por uma pessoa, como resultado de uma combinação satisfatória, de variáveis meteorológicas, com a atividade lá desenvolvida e com a vestimenta usada pelas pessoas, em determinado ambiente.

Os índices de conforto térmico humano envolvem variáveis atmosféricas e fisiológicas, mas também existem índices, como o Índice de Desconforto (ID), o Temperatura Efetiva (TE) e o Índice de Temperatura e Umidade (ITU), que equacionam apenas variáveis meteorológicas. A vantagem desses índices se deve ao fato de que são mais fáceis de aplicar por não necessitarem de variáveis fisiológicas dos seres humanos, visto que não se conseguem com facilidade. Tratam-se de classificações climáticas, neste caso, da espacialização das zonas de conforto humano.
Dessa forma, nessa pesquisa optou-se por trabalhar com três índices de conforto térmico humano cientificamente reconhecidos e de fácil aplicação, quais sejam: ID, TE e ITU, equações 1 , 2 e 3 respectivamente, enquanto que as classes de qualificação estão descritas nas Tabelas 2, 3 e 4.

$$
I D=T-0,55(1-0,01 U R)
$$

Sendo:

$I D$-Índice de Desconforto em $\left({ }^{\circ} \mathrm{C}\right)$; $T$ - temperatura do bulbo seco $\left({ }^{\circ} \mathrm{C}\right)$; $U R$ - Umidade Relativa do ar (\%).

De posse dos valores do ID, categorizou-se as respectivas classificações baseando-se no nível de desconforto, conforme Tabela 2.

Tabela 2. Índices de Desconforto humano (ID) e suas respectivas classificações.

\begin{tabular}{cc}
\hline ID $\left({ }^{\mathbf{}} \mathbf{C}\right)$ & $\begin{array}{c}\text { Nível de desconforto } \\
\text { térmico }\end{array}$ \\
\hline ID $<21,0$ & Não há desconforto \\
$21,0 \leq$ ID $<24,0$ & Menos de $50 \%$ da população \\
& sente desconforto \\
$24,0 \leq$ ID $<27,0$ & $\begin{array}{c}\text { Aprox. } 50 \% \text { da população } \\
\text { sente desconforto }\end{array}$ \\
$27,0 \leq$ ID $<29,0$ & A maioria da população sofre \\
& desconforto
\end{tabular}




$$
\begin{gathered}
29,0 \leq \mathrm{ID}<32,0 \quad \begin{array}{c}
\text { Todas as pessoas sentem } \\
\text { estresse severo }
\end{array} \\
T E=T-0,4(T-10)\left(1-\frac{U R}{100}\right)
\end{gathered}
$$

Em que:

$T E$ - temperatura efetiva $\left({ }^{\circ} \mathrm{C}\right)$.

A classificação da $T E$ está descrita na Tabela 3.

Tabela 3 - Valores de temperatura efetiva $\left({ }^{\circ} \mathrm{C}\right)$ e as respectivas descrições da sensação humana.

\begin{tabular}{cc}
\hline $\begin{array}{l}\text { Temperatura } \\
\text { Efetiva }\end{array}$ & $\begin{array}{l}\text { Descrição da } \\
\text { humana }\end{array}$ \\
\hline $\mathrm{TE}>30$ & Muito quente \\
$24 \leq \mathrm{TE}<30$ & Moderão \\
$12 \leq \mathrm{TE}<24$ & Agradánel quente \\
$6 \leq \mathrm{TE}<12$ & Fresco \\
$0 \leq \mathrm{TE}<6$ & Muito Fresco \\
$-12 \leq \mathrm{TE}<0$ & Frio \\
$-24 \leq \mathrm{TE}<-12$ & Muito Frio \\
$-30 \leq \mathrm{TE}<-24$ & Perigo de Congelamento \\
& (início) \\
$\mathrm{TE}<-30$ & Perigo de Congelamento \\
& (aumento) \\
\hline
\end{tabular}

Fonte: Hentschel 1986 apud Suping et al., (1992).

$$
I T U=0,8 T+\left(U R-\frac{T}{500}\right)
$$

Sendo:

ITU - índice de temperatura e umidade relativa do ar.

Para a classificação do ITU foram utilizadas descrições propostas por Nóbrega e Lemos (2011), de acordo com a Tabela 4.

Tabela 4. Índice de Temperatura e umidade com as respectivas categorias de sensação.

\begin{tabular}{rc}
\hline ITU & Sensação Térmica \\
\hline $21 \leq$ ITU $\leq 24$ & Confortável \\
$24 \leq$ ITU $\leq 26$ & Levemente desconfortável \\
ITU $>26$ & Extremamente desconfortável \\
\hline
\end{tabular}
Fonte: Nóbrega e Lemos (2011).

Informações importantes sobre os índices de conforto humano aqui utilizados podem ser encontradas nos trabalhos de Matzarakis e Mayer
ID $\geq 32,0 \quad$ Estado de emergência médica Fonte: Matzarakis; Mayer (1991).

(1991); Suping et al. (1992), Nedel et al. (2006), Santos (2011) e principalmente no trabalho de Blazejczyc (2012), que explicam e comparam vários índices de conforto térmico humano.

\section{Resultados e Discussões}

Em termos comparativos à temperatura média registrada no período de 1 mês, em todos os pontos, registrou uma diferença de $1,8^{\circ} \mathrm{C}$ entre a maior e menor média, sendo a maior registrada no $\mathrm{P} 10$ (avenida principal), com $30,6^{\circ} \mathrm{C}$ e a menor média registrada no $\mathrm{P} 7$ (rua arborizada) de $28,8^{\circ} \mathrm{C}$.

As diferenças entre as temperaturas médias tendem a ser baixas uma vez que a média aritmética suaviza as diferenças enquanto os valores de temperatura absolutos trazem diferenças mais expressivas.

As maiores diferenças detectadas para o período analisado foram com relação às temperaturas máximas absolutas, essas detectadas entre as 13 e $15 \mathrm{~h}$, sendo a temperatura máxima absoluta registrada em Caicó de $42,7^{\circ} \mathrm{C}$ no $\mathrm{P} 2$ (Poente) no dia 05/05, e a menor temperatura máxima de $37,3^{\circ} \mathrm{C}$ registrada no $\mathrm{P} 11$ (área rural) no dia 28/05, constatando-se que na área urbana a temperatura máxima do ar foi $5,4^{\circ} \mathrm{C}$ maior comparada a uma área com aspecto rural. Para o mesmo dia e hora $(05 / 05)$ às $14 \mathrm{~h}$, a temperatura máxima registrada na área rural foi de $36,4^{\circ} \mathrm{C}$, apresentando uma amplitude de $6,3^{\circ} \mathrm{C}$ entre o ponto mais quente da área urbana e a área rural. Dentro da área urbanizada, essa diferença de temperatura entre os pontos diminuiu para $3,9^{\circ} \mathrm{C}$, do $\mathrm{P} 2$ (Poente) $42,7^{\circ} \mathrm{C}$ para o $\mathrm{P} 9$ (Periferia) que registrou a menor temperatura máxima absoluta em área urbana, de $38,8^{\circ}$.

Quanto às temperaturas mínimas observadas, essas registradas entre 04 e $05 \mathrm{~h} 40$, a diferença registrada foi menor, sendo de $2,5^{\circ} \mathrm{C}$ entre o P10 (Av. principal) com $22,7^{\circ} \mathrm{C}$ no dia 04/06 e o P11 (área rural) com $20,2^{\circ} \mathrm{C}$ no dia $27 / 05$. Dentro do próprio ambiente urbanizado essa diferença foi de $2,3^{\circ} \mathrm{C}$ entre o $\mathrm{P} 10$, que registrou a maior temperatura mínima de $22,7^{\circ} \mathrm{C}$ e o $\mathrm{P} 6$ (Alto terra) que registrou a menor temperatura mínima em área urbana de $20,4^{\circ} \mathrm{C}$.

Em se tratando de temperaturas elevadas, os dados observados na Tabela 5, apresentam o número de vezes em que se registrou determinada faixa de temperatura $\left(\geq 35^{\circ} \mathrm{C}\right.$ e $\left.\geq 40^{\circ} \mathrm{C}\right)$ em cada ponto. 
Tabela 5. Número com registros de temperaturas superiores a $35^{\circ} \mathrm{C}$ e $40^{\circ} \mathrm{C}$, em cada ponto.

\begin{tabular}{lcc}
\hline \multicolumn{1}{c}{ Pontos } & $\begin{array}{c}\mathbf{N}^{\circ} \text { de registros } \\
\mathbf{3 5 5}^{\circ} \mathbf{C}\end{array}$ & $\begin{array}{c}\mathbf{N}^{\circ} \text { de registros } \\
\mathbf{2 4 0 ^ { \circ } \mathbf { C }}\end{array}$ \\
\hline P1 - Nascente (Paraíba) & 142 & 0 \\
P2 - Poente (Coacal) & 194 & 57 \\
P3 - Vale (João XXIII) & 90 & 1 \\
P4 - Alto pedra (Picanço) & 126 & 2 \\
P5 - Rua estreita (Centro) & 135 & 0 \\
P6 - Alto terra (CAIC) & 140 & 1 \\
P7 - Rua arborizada (Centro) & 24 & 0 \\
P8 - Rua de barro (Recreio) & 116 & 0 \\
P9 - Periferia (Samanaú) & 99 & 0 \\
P10 - Avenida principal & 187 & 21 \\
(Coronel Martiniano) & & \\
P11 - Área rural & 76 & 0 \\
(pousada Céu Azul) & & \\
\hline
\end{tabular}

A partir da análise dos valores máximos e mínimos de temperaturas do ar registrados, pôdese perceber que o P10 e P2, foram aqueles que registraram as temperaturas médias mais elevadas, registrando-se respectivamente, $30,6^{\circ} \mathrm{C}$ e $30,4^{\circ} \mathrm{C}$. Nesses pontos as temperaturas máximas atingiram valores de $42,7^{\circ} \mathrm{C}$ e $41,7^{\circ} \mathrm{C}$, respectivamente. O P2 foi ainda o que apresentou o maior número de ocorrências iguais ou superiores aos $35^{\circ} \mathrm{C}$ e também $\geq 40^{\circ} \mathrm{C}$, comparado aos demais pontos (Tabela 5). Enquanto que o P10 apresentou o segundo maior número de registros de temperaturas $\geq 40^{\circ} \mathrm{C}$ e também $\geq 35^{\circ} \mathrm{C}$. Esses dois pontos podem ser, portanto, considerados os mais quentes, entre os analisados, da cidade de Caicó.

Essas características de maiores temperaturas do ar, no P10 (Figura 4A) e P2 (Figura 4B), deve-se à urbanização intensificada para essas localidades do referido município, com presença de ruas pavimentadas (asfalto ou paralelepípedo), muitos prédios, fluxo de veículos, e pouca arborização. Por outro lado, no P11, (Figura 4C), localizado na área rural, foram registrados os menores valores de temperatura máxima $\left(37,3^{\circ} \mathrm{C}\right)$ e mínima $\left(20,2^{\circ} \mathrm{C}\right)$, assim como a segunda menor temperatura média $\left(28,9^{\circ} \mathrm{C}\right)$, e não houve registro de temperatura $\geq 40^{\circ} \mathrm{C}$. Destacase que o P7, Figura 4D, foi o que registrou a menor temperatura média $\left(28,8^{\circ} \mathrm{C}\right)$ e menor amplitude térmica $\left(17,6^{\circ} \mathrm{C}\right)$, mesmo estando esse ponto em zona urbana, isso ocorreu devido à presença densa de árvores no local, culminando em temperaturas menores, no período de análise.

Os pontos 9 (periferia) e 3 (vale), também registraram médias mais baixas se comparadas aos demais pontos na área urbana, menos que 100 registros com temperaturas superiores aos $35^{\circ} \mathrm{C}$, com destaque para o P9 (periferia) (Tabelas 5). 

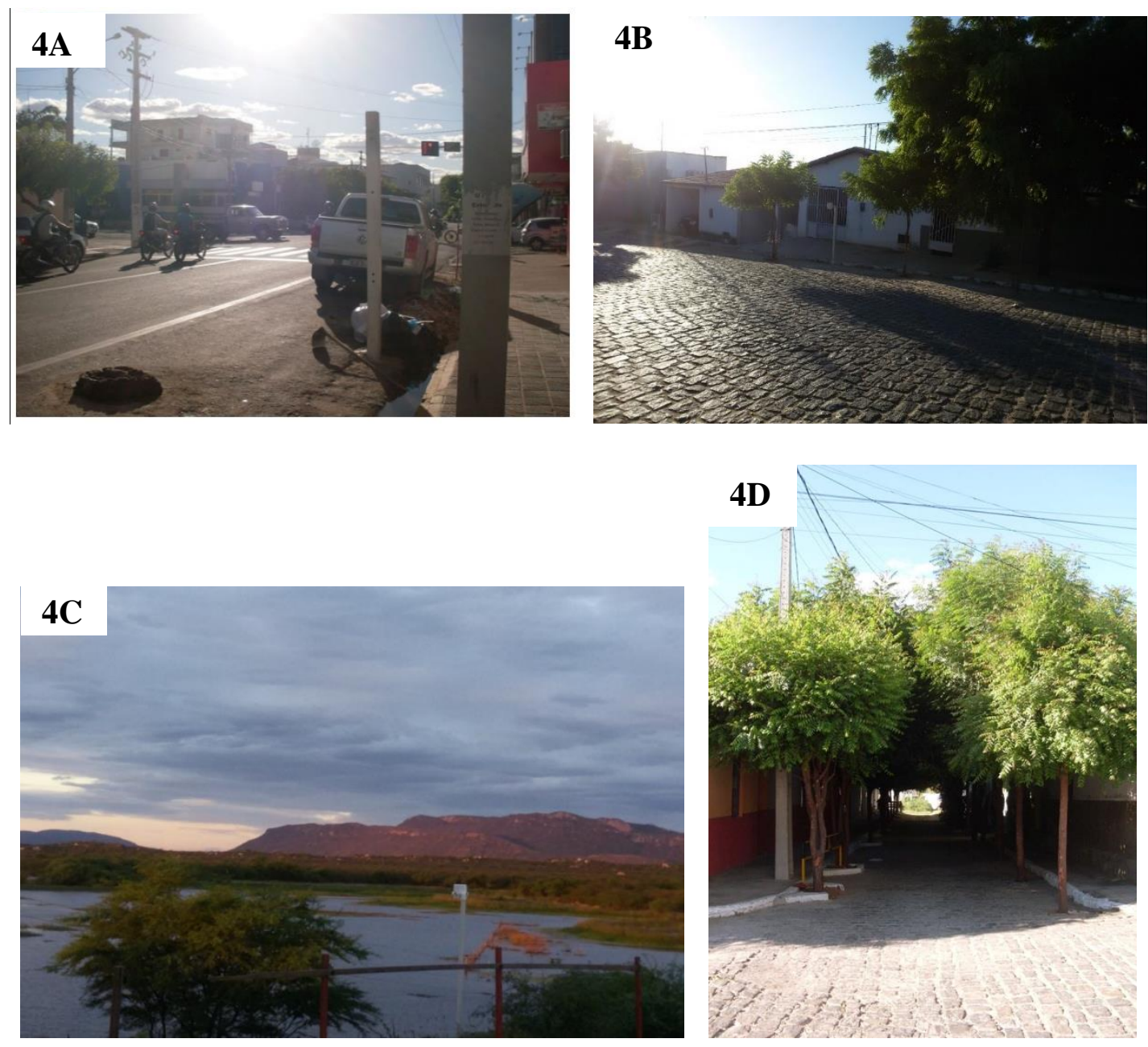

Figura 4 - Imagens dos pontos que obtiveram destaques nos registros de temperaturas máximas no município de Caicó, localizadas no P10 (4A), P2 (4B), e dos registros de temperaturas mais amenas P11 (4C área rural) e P7 (4D).

Quanto a análise da sensação térmica, foram realizadas médias diárias assim como a análise para a hora mais quente e mais fria do dia para todos os pontos em questão. Analisando o Índice de Desconforto (ID) aplicado, todos os dias (média diária) estiveram fora da zona de conforto humano para todos os pontos em Caicó. Entretanto, dois pontos da cidade, o P2 (Poente) e o P10 (Av. principal), apresentaram a pior condição quanto à sensação térmica, alcançando valores superiores a $27^{\circ} \mathrm{C}$, que, segundo este índice, significa que "maior parte da população sente desconforto devido ao calor". Sendo que em 4 dias do mês tiveram esse registro no $\mathrm{P} 10$ (av. principal) e 3 dias do mês no P2 (Poente), como pode ser verificado na Figura 5. 


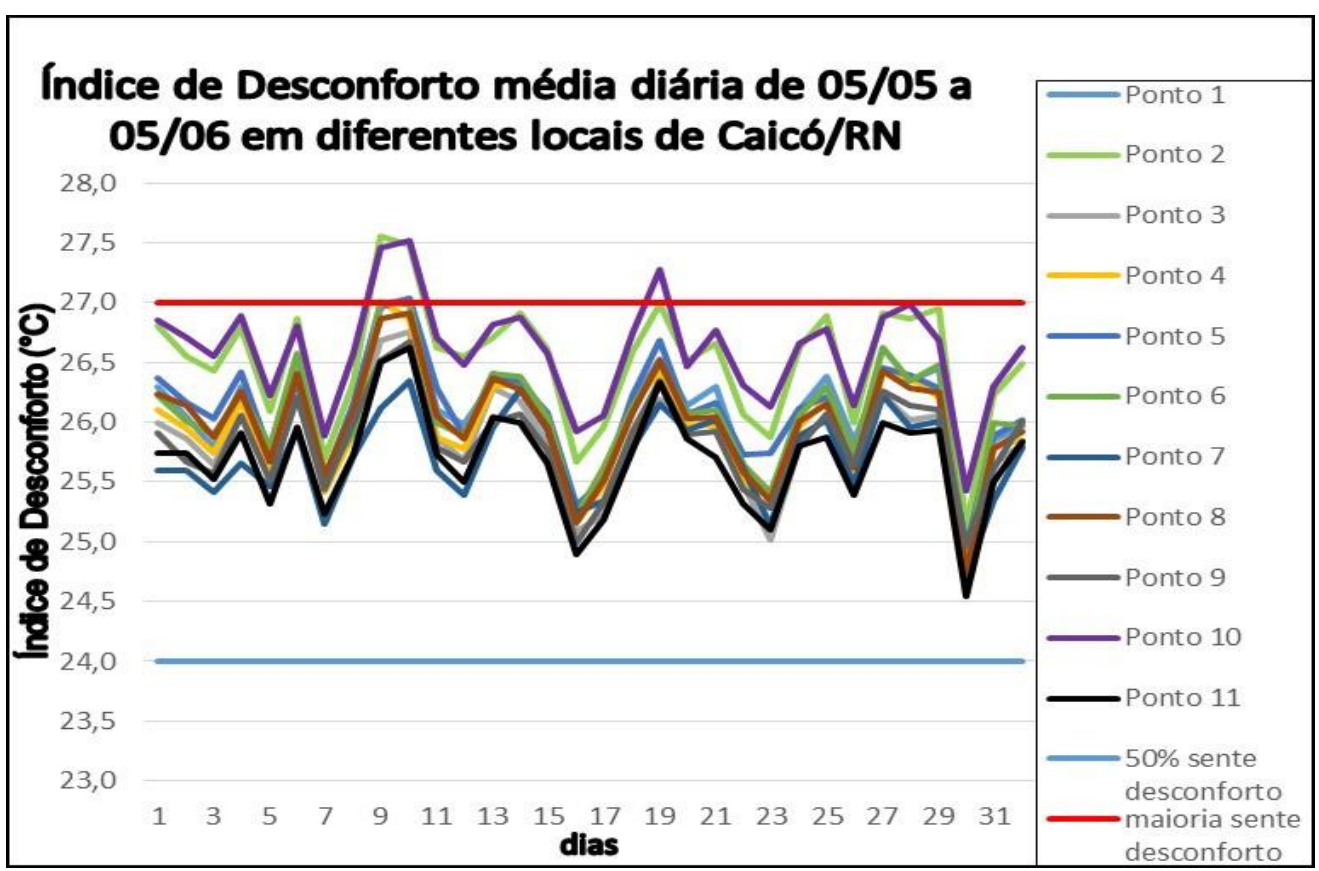

Figura 5. Índice de Desconforto, média diária de 05/05 a 05/06 em diferentes locais de Caicó/RN.

De acordo com o índice de Temperatura Efetiva (TE), as médias diárias em todos os pontos analisados foram classificados como "calor moderado", não havendo distinção detectável entre os diferentes pontos da cidade quando aplicado esse índice (Figura 6).

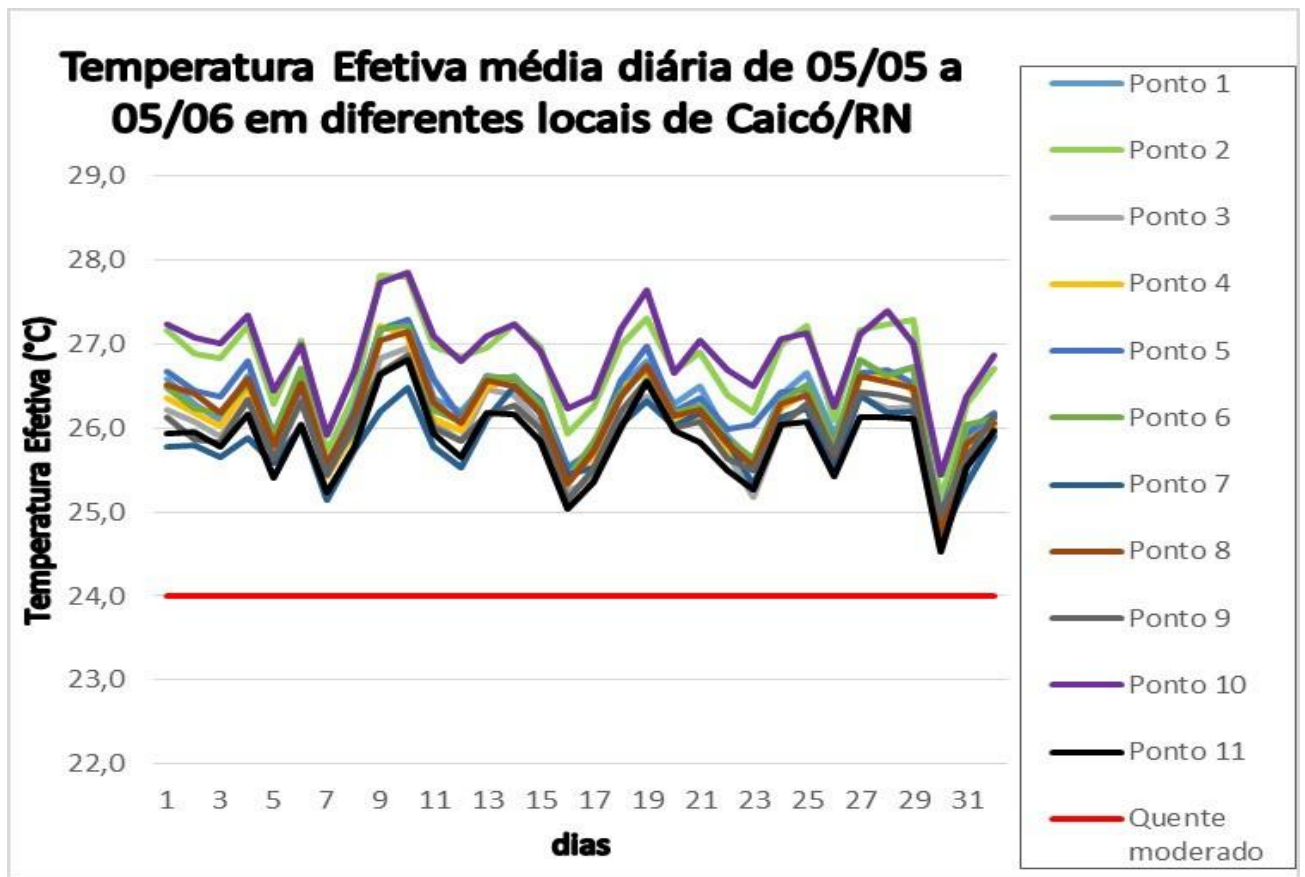

Figura 6. Temperatura Efetiva, média diária de 05/05 a 05/06 em diferentes locais de Caicó/RN.

Quando se aplicou o Índice de Temperatura e Umidade (ITU), Figura 7, exceto nos dias 07/05 e 30/05, todos os pontos apresentaram-se como extremamente desconfortável devido ao calor. No dia 30/05 todos os pontos apresentaram leve desconforto devido ao calor. O P11 (área rural, representado pela linha cor preta) apresentou predominantemente o menor desconforto (leve

Lucena, R. L., Cabral Júnior, J. B., Steinke, E. T. 
desconforto devido ao calor), para o período analisado, quando da aplicação do ITU.

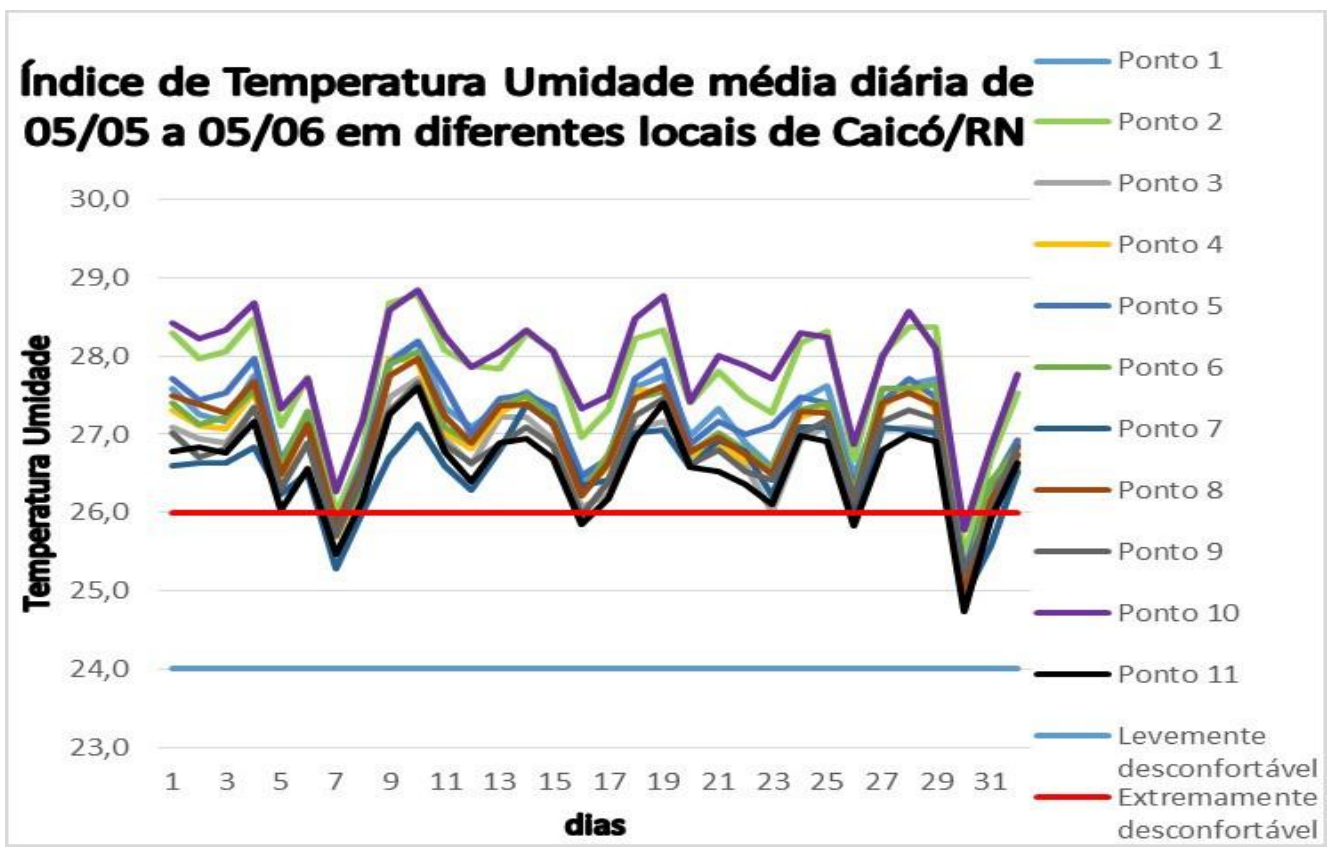

Figura 7. Índice de Temperatura Umidade, média diária de 05/05 a 05/06 em diferentes locais de Caicó/RN.

Além dos valores diários médios de temperatura do ar observados, realizou-se a aplicação dos três índices de conforto térmico para a hora mais fria e mais quente do dia. Conforme explica Varejão-Silva (2006) o valor máximo diário da temperatura do ar ocorre normalmente cerca de duas horas depois do ponto mais elevado do Sol, enquanto que a temperatura mínima diária ocorre minutos antes do nascer do Sol.

Os horários das temperaturas máximas ocorreram predominantemente às $14: 30 \mathrm{~h}$ e as mínimas por volta das 04:30h. Desse modo, os resultados mostram uma grande diferença da média diária uma vez que todos os pontos irão apresentar uma mudança significativa quanto a sensação térmica detectada no decorrer do dia.

Para o Índice de Desconforto (ID), Figura 8, os pontos 2 (Poente) e 10 (Av. principal) apresentaram por volta das $14: 30 \mathrm{~h}$ valores de ID superiores a $29^{\circ} \mathrm{C}$, situação em que se classifica como: todas as pessoas sentem desconforto devido ao calor. Os demais pontos apresentaram para esta mesma hora valores superiores a $27^{\circ} \mathrm{C}$, cuja classificação é: a maioria da população sente desconforto devido ao calor. Destaque para os pontos 1 (Nascente/Paraíba) e 5 (Rua estreita/Centro) que atingiram o valor de $29^{\circ} \mathrm{C}$, mas não o ultrapassaram. Porém, por volta das 04:30h todos os 11 pontos de Caicó registraram valores de ID inferiores a $24^{\circ} \mathrm{C}$, significando que $50 \%$ da população sente desconforto.

Desse modo, diferente dos valores médios diários apresentados anteriormente que mostravam que a maioria da população sente desconforto devido ao calor, quando observada a variação entre dia e noite, a sensação térmica diária varia de $50 \%$ da população sente desconforto para a maioria da população sente desconforto, atingindo um máximo classificado como todos sentem desconforto, para as localidades P2 e P10. 


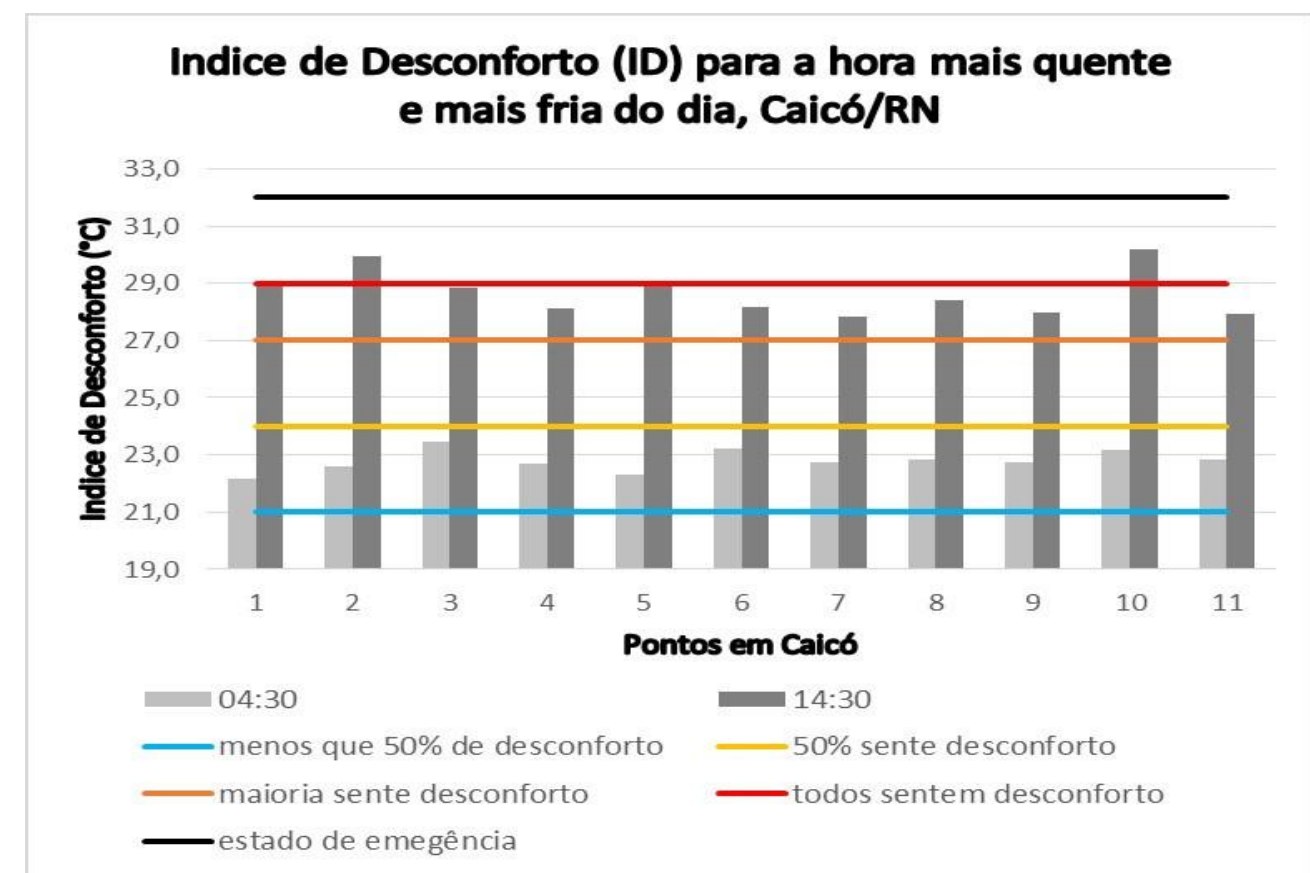

Figura 8. Índice de Desconforto (ID) para a hora mais quente e mais fria do dia, Caicó/RN.

Aplicando o índice de Temperatura Efetiva (TE), percebe-se que todos os 11 pontos apresentaram sensação térmica agradável por volta das 04:30h (Figura 9). Nove pontos de Caicó registraram calor moderado próximo ao horário das 14:30h. Mais uma vez, os pontos 2 e 10 apresentaram valores de TE superiores a $30^{\circ} \mathrm{C}$, classificando esses dois lugares como muito quentes, durante este período da tarde. Vale destacar que os pontos 1 e 5 atingiram o valor de TE de $30^{\circ} \mathrm{C}$, mas como não foi superior a este, ainda foram classificados como quente moderado.

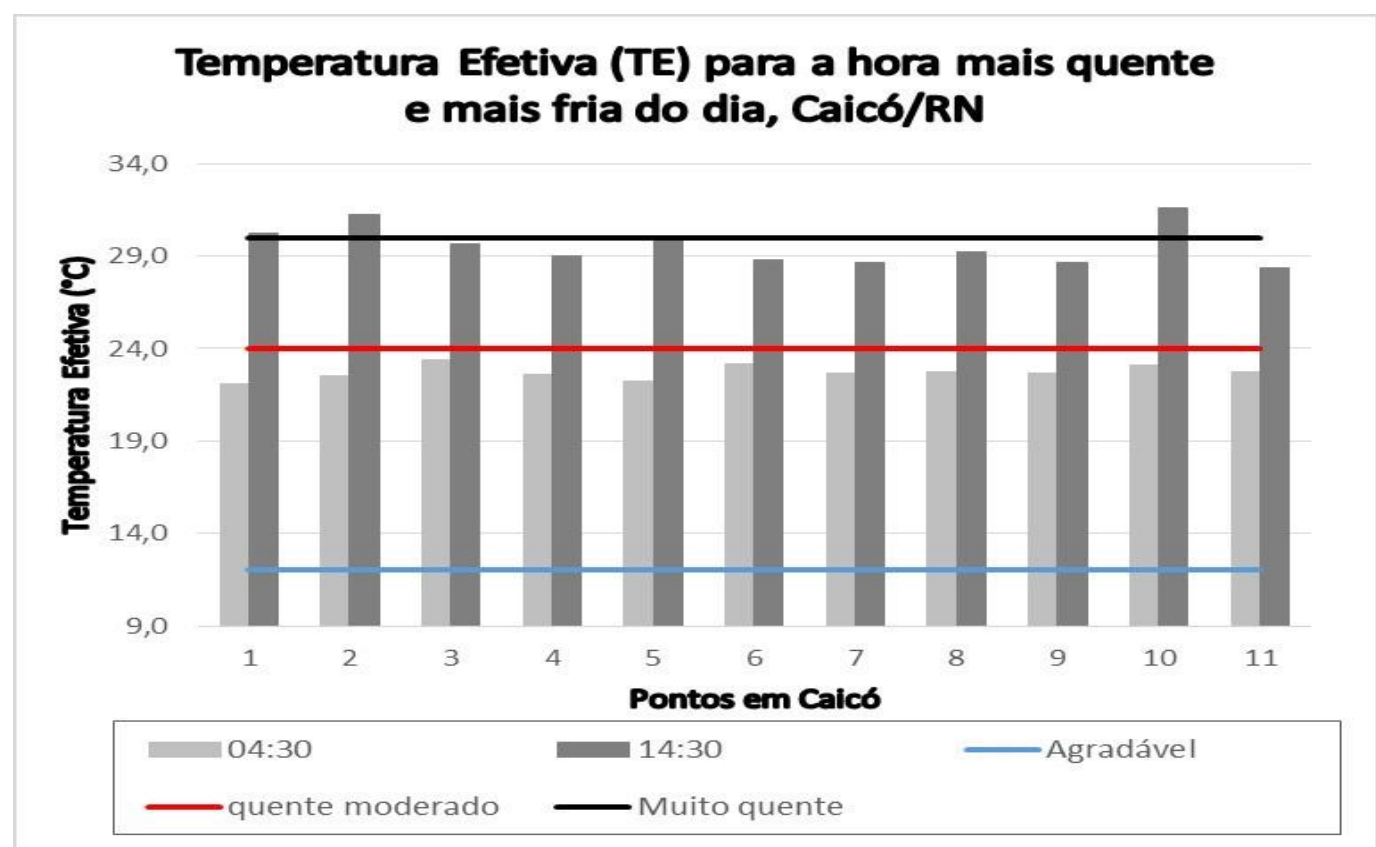

Figura 9. Índice de Temperatura Efetiva para a hora mais quente e mais fria do dia, Caicó/RN.

Para o Índice de Temperatura e Umidade (ITU) todos os pontos em questão apresentaram-se com sensação térmica confortável para as 04:30h e atingiram classificação de extremamente desconfortável, devido ao calor, por volta das

Lucena, R. L., Cabral Júnior, J. B., Steinke, E. T. 14:30h. Portanto, segundo este índice, todos os pontos apresentaram o mesmo comportamento, ou seja, uma elevada variação na sensação térmica entre dia e noite indo desde confortável até 
extremamente desconfortável, como pode ser verificado na Figura 10.

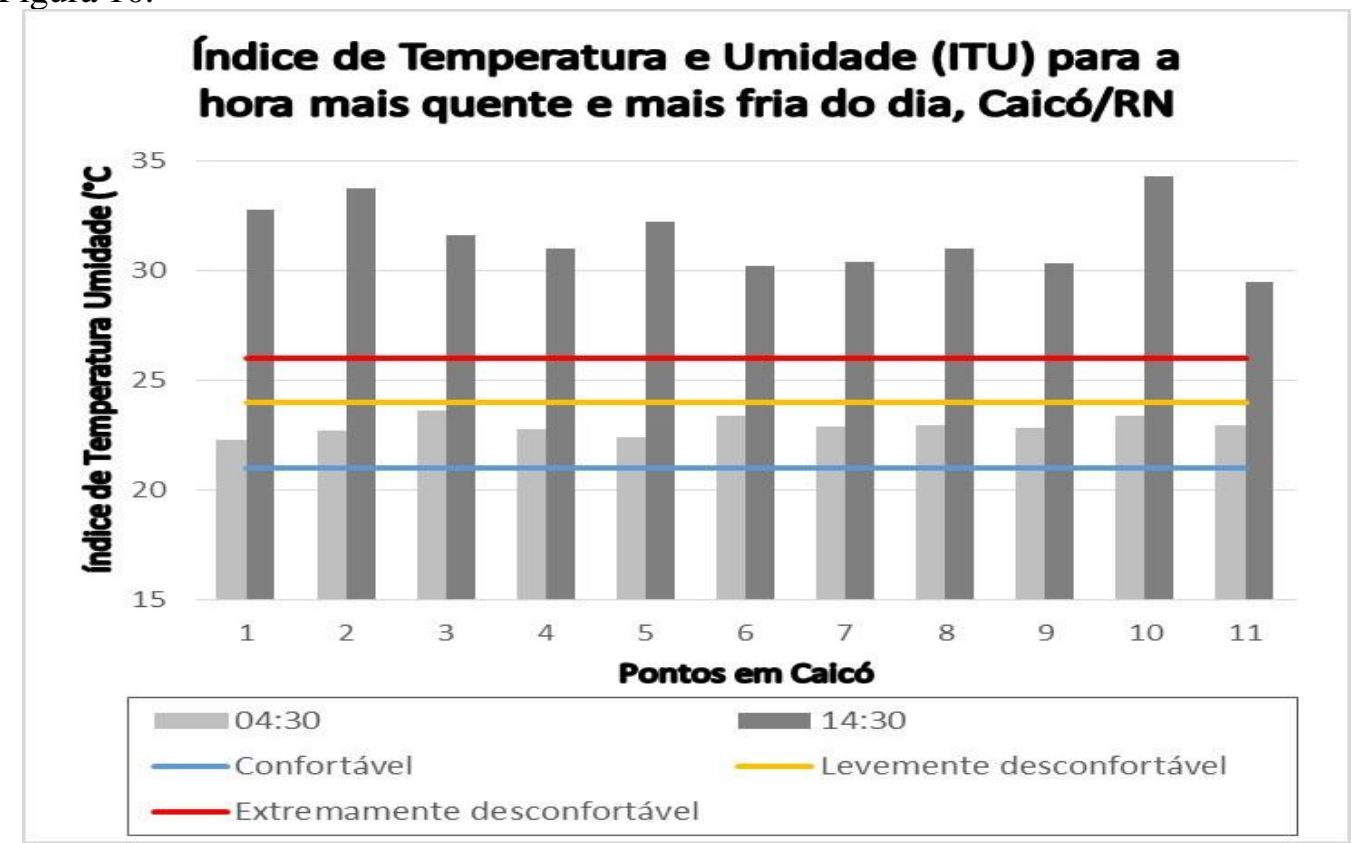

Figura 10. Índice de Temperatura e Umidade para a hora mais quente e mais fria do dia, Caicó/RN.

Estudos de clima urbano realizados por Bourbia e Boucheriba (2010), Ferreira et al. (2019) e Silva et al. (2020), mostraram que áreas com pouca cobertura vegetal, densamente urbanizadas e com alta impermeabilidade possuem uma resposta térmica mais elevada sendo, por tanto, necessárias medidas para reduzir o desconforto térmico em

\section{Conclusões}

De acordo com os resultados encontrados nessa pesquisa, foi possível constatar que o município de Caicó-RN, de clima semiárido, apresentou diferenças internas marcantes (na área urbanizada), diferenças essas ainda mais acentuadas quando se comparou a área urbana com a rural.

Os pontos mais quentes e que obtiveram os resultados mais extremos com relação a sensação térmica e desconforto humano foram os pontos $2 \mathrm{e}$ 10, cujas características principais foram: presença de pavimentos, construções, quase ausência de arborização, etc. Ressalta-se ainda que no P2 a insolação recebida é proporcional a insolação disponível devido a rua está no sentido LesteOeste, portanto, entre o nascer e o ocaso do Sol a incidência de radiação é total (sem obstáculo que gere sombreamento). Enquanto que no P10, não se descarta que haja contribuição dos gases derivados do carbono, emitidos pelo intenso fluxo de veículos, que podem estar contribuindo para o aquecimento local, além da temperatura do asfalto. áreas urbanas com tais características. A medida mais eficaz para reduzir esses efeitos térmicos negativos é a expansão de espaços verdes no contexto urbano, sugerido, em alguns estudos, pelos próprios habitantes locais (Gomes; Caracristi, 2019; Maskooni et al., 2020).

Para os pontos localizados em áreas com presença de cobertura vegetal (área rural ou urbana), foram registradas as menores temperaturas, a exemplo do P11 (área rural/pousada Céu Azul) e do P7 (centro da cidade).

É importante enfatizar que as análises experimentais realizadas neste trabalho foram referentes a um período cuja temperatura média do ar é relativamente mais baixa (maio-junho) comparada ao período mais quente do ano (estação do verão), sugerindo-se que no solstício de verão os resultados de desconforto térmico humano tendem a ser intensificados.

Desse modo, é importante destacar que os resultados alcançados servem de subsídio ao crescimento urbano da cidade de forma planejada, uma vez que indica práticas adequadas e inadequadas para a obtenção do conforto térmico humano. A proximidade de áreas verdes, assim como a arborização urbana, produz um microclima mais agradável que possibilitam uma melhor sensação térmica e, portanto, mais conforto e qualidade de vida para uma população que já vive numa região semiárida, naturalmente muito quente,

Lucena, R. L., Cabral Júnior, J. B., Steinke, E. T. 
Revista Brasileira de Geografia Física v.13, n.07 (2020) 3287-3303.

como é o caso da depressão sertaneja onde se encontra o município de Caicó. 


\section{Agradecimentos}

Externamos aos revisores da Revista Brasileira de Geografia Física (RBGF), por dispor de tempo para ler e avaliar este trabalho, cujos resultados são da Tese de Doutorado da primeira autora.

\section{Referências}

Ab'saber, A. N., 2002. "Caatingas: o domínio dos sertões secos". Os domínios de natureza no Brasil: Potencialidades paisagísticas. $6^{\mathrm{a}} \mathrm{Ed}$., São Paulo: Ateliê Editorial.

Almeida, H. A., Cabral Júnior, J. B., 2014. Variabilidades sazonais e interdecadais da chuva nas microrregiões geográficas do estado da Paraíba. Revista Brasileira de Geografia Física, v. 07. Disponível: https://periodicos.ufpe.br/revistas/rbgfe/articl e/view/233346

Andreasi, W. A., Lamberts, R., Cândido, C., 2010. Thermal acceptability assessment in buildings located in hot and humid regions in Brazil. Building and Environment, v. 45, n. 5, p. 1225-1232.

Disponível: https://doi.org/10.1016/j.buildenv.2009.11.00 $\underline{5}$

Blazejczyk, K., Epstein, Y., Jendritzky, G., Staiger, H., Tinz, B., 2012. Comparison of UTCI to selected thermal indices. International Journal of Biometeorology, v. 56, p.515-535. Disponível: https://doi.org/10.1007/s00484011-0453-2

Bourbia, F., Boucheriba, F. Impact of street design on urban microclimate for semi arid climate (Constantine). 2010. Renewable Energy 35. P. 343-347.

Disponível: https://doi.org/10.1016/j.renene.2009.07.017

Cabral Júnior, J. B., Almeida, H. A., Silva, C. M. S., 2013. Análise Comparativa da Temperatura Média do Ar em Campina Grande, PB, Obtida pelo Método dos Extremos e pelo Método Padrão. Revista Brasileira de Geografia Física, v. 6, p. 888902, 2013.2 Disponível: https://doi.org/10.26848/rbgf.v6i4.233083

Cabral Júnior, J. B., Bezerra, B. G., 2018. Análises da evapotranspiração de referência e do índice de aridez para o Nordeste do Brasil. Revista de Geociências do Nordeste [online], v. 4, n. 1, p. 71-89. Disponível: https://periodicos.ufrn.br/revistadoregne/artic le/view/14746

Cabral Júnior, J. B., Lucena, R. L., 2020. Analysis of precipitation by non-parametric tests of Mann-Kendall and Kruskal-Wallis. Mercator [online], v. 19, p. 1-14. Disponível: https://doi.org/10.4215/rm2020.e19001

Cabral Júnior, J. B., Silva, C. M. S., Almeida, H. A., Bezerra, B. G., Spyrides, M. H. C., 2019. Detecting linear trend of reference evapotranspiration in irrigated farming areas in Brazil's semiarid region. Theoretical And Applied Climatology, v. 138. Disponível: https://doi.org/10.1007/s00704-019-02816-w

Correia Filho, W. L. F., Santiago, D. de B., Oliveira-Júnior, J. F. de., Junior, C. A. da S. 2019. Impact of Urban Decadal Advance on Land Use and Land Cover and Surface Temperature in the City of Maceió, Brazil. Land Use Policy. 87. Disponível: https://doi.org/10.1016/j.landusepol.2019.104 $\underline{026}$

Faria, C. E. de., 2011. Os eventos geográficos e a expansão urbana de Caicó. Natal: Editora do IFRN.

Gartland, L., 2010. Ilhas de calor: como mitigar zonas de calor em áreas urbanas. Tradução Silvia Helena Gonçalves. São Paulo: Oficina de Textos.

Gomes, Y. B., Caracristi, I., 2020. Clima urbano e percepção térmica dos moradores das pequenas cidades do Semiárido: uma análise da cidade de Forquilha (CE). Revista Homem, Espaço E Tempo, 2019. 13(2). Disponível: https://rhet.uvanet.br/index.php/rhet/article/vi $\underline{\mathrm{ew} / 344}$

Instituto Brasileiro de Geografia e Estatística (IBGE, 2018). Brasil. Disponível em: https://cidades.ibge.gov.br/brasil/rn/caico/pan orama. Acesso em 15 de Jul de 2019.

Lamberts, R., Dutra, L., Pereira, F. O. R., 1997. Eficiência energética na arquitetura. São Paulo: PW.

Landsberg, H. E., 1956. The climate of towns. In: THOMAS W. E. ec. Man's role in changing

Lucena, R. L., Cabral Júnior, J. B., Steinke, E. T. 
the face of Earth. The WennerGren Fundation Antropological Research. The University of Chicago Press.

Lombardo, M. A., 1985. Ilhas de calor nas metrópoles: o exemplo de São Paulo. São Paulo: HUCITEC.

Lucena, J. A., Souza, B.I., Moura, M. De O., Lima, J. De O., 2012. Análise da variabilidade da precipitação pluviométrica como subsídio para o planejamento agrícola em Caicó/RN. Revista Brasileira de Climatologia, v.10. Disponível: http://dx.doi.org/10.5380/abclima.v10i1.3059 $\underline{1}$

Lucena, R. L., Cabral Júnior, J. B., Steinke, E. T., 2018. Comportamento Hidroclimatológico do Estado do Rio Grande do Norte e do Município de Caicó. Revista Brasileira De Meteorologia, v. 33. Disponível: http://dx.doi.org/10.1590/0102-7786333008

Lucena, R. L., Ferreira, A. M., Ferreira, H. F. P. A., Steinke, E. T., 2013. Variabilidade climática no município de Caicó/RN: secas e chuvas num arquétipo do clima semiárido do Nordeste brasileiro. CLIMEP Climatologia e Estudos da Paisagem, v.8. p. 25-47. Disponível:https://www.periodicos.rc.bibliote ca.unesp.br/index.php/climatologia/article/vie $\underline{\mathrm{w} / 8117}$

Lucena, R. L., SANTOS, T. H. F., FERREIRA, A. M. , STEINKE, E. T., 2016. Heat and human comfort in a town in Brazil's semi-arid region. The International Journal of Climate Change: Impacts and Responses, v. 8, p. 15-30. Disponível: https://doi.org/10.18848/18357156/CGP/v08i04/15-30

Maskooni, E. K., Hashemi, H., Berndtsson, R., Arasteh, P. D., Kazemi, M., 2020. Impact of spatiotemporal land-use and landcover changes on surface urban heat islands in a semiarid region using Landsat data, Int. J. of Digital Earth. Disponível: https://doi.org/10.1080/17538947.2020.1813 $\underline{210}$

Matzarakis, A., Mayer, H. 1991. The extreme heat wave in Athens in July 1987 from the point of view of human biometeorology. Atmospheric environment. $25 \mathrm{~b}$. Disponível: https://doi.org/10.1016/0957-1272(91)90055$\underline{\mathrm{J}}$

Monteiro, C. A. De F., 1976. Teoria e clima urbano. São Paulo: IGEO/USP.

Monteiro, C. A. De F., MENDONÇA, F., 2003. Clima Urbano. São Paulo: Contexto.

Nedel, A. S., Coelho, M. De S., Gonçalves, F. L. T., 2006. Comparative analysis of different human thermal comfort indexes in São Paulo city and their relationship with respiratory morbidity. Proceedings of 8 ICSHMO, Foz do Iguaçú, Brazil, April 24 -28, INPE, p.675-677.

Neves, G. A. R., Marques, J. B., Nogueira, J. De S., Biudes, M. S., Arruda, P. H. Z., Curado, L. F. A., Palácios, F. Da R., 2015. Desenvolvimento e Calibração de um Termohigrômetro para uso em Pesquisas de Micrometeorologia, Agrometeorologia e Climatológica. Revista Brasileira de Geografia Física. v 08. n 01. Disponível: https://doi.org/10.26848/rbgf.v8.1.p136-143

Nóbrega, R. S., Lemos, T. V. Da S., 2011. O microclima e o (des)conforto térmico em ambientes abertos na cidade do Recife. Revista de Geografia (UFPE), v.8, n.1. Disponível:

https://periodicos.ufpe.br/revistas/revistageog rafia/article/view/228942/23352

Romero, M. A. B., 2013. Princípios bioclimáticos para o desenho urbano. Brasília: Editora Universidade de Brasília.

Santos, J. S., 2011. Campo térmico urbano e a sua relação com o uso e cobertura do solo em cidade de clima tropical úmido. Tese de Doutorado, Programa de Pós-graduação em Recursos Naturais, Universidade Federal de Campina Grande (UFCG), 110p..

Shashua-Bar, L., Porshter, O., Bitan, A., Yaakov, Y., 2010. Microclimate modelling of street tree species effects within the varied urban morphology in the Mediterranean city of Tel Aviv, Israel. International Journal of Climatology, v. 30, p. 44-57. Disponível: https://doi.org/10.1002/joc.1869

Silva, G., Souza, S., Cabral Júnior, J. B., Lucena R., 2020. Influência da arborização na modificação microclimática em cidades de pequeno porte do Semiárido brasileiro: $\mathrm{o}$

Lucena, R. L., Cabral Júnior, J. B., Steinke, E. T. 
estudo de caso de Caicó. Rev. Geogr. Acadêmica. v.14, n.1. Disponível: https://revista.ufrr.br/rga/article/view/6191

Silva, N. R. da., 2007. Avaliação do conforto térmico. (Trabalho de conclusão de curso) Engenharia de segurança do trabalho. Universidade Santa Cecília, Santos SP. 35p.

Suping, Z., Guanglin, M., Yanwen, W., Ji, L. 1992. Study of the relationships between weather conditions and the marathon race, and os meteorotropic affects on distance runners. International Journal of Biometeorology. v.36. Disponível: https://doi.org/10.1007/BF01208915
Taha, H. 1997. Urban climates and heat islands: albedo, evapotranspiration, and anthropogenic heat. Energy and Buildings. Disponível: https://doi.org/10.1016/S03787788(96)00999-1

Ting, D. S.-K., 2012. Heat Islands - Understanding and Mitigating Heat in Urban Areas. [s.l.] Earthscan LLC.

Varejão-Silva, M. A., 2006. Meteorologia e Climatologia. $5^{\text {a }}$ ed. Recife/PE: PAX Gráfica e Editora Ltda, 345p.

Zavattini, J. A., 2004. Estudos do clima no Brasil. Campinas - SP: Editora Alínea, 398p. 